\title{
Comment on "Currently available and experimental dyes for intraoperative near-infrared fluorescence imaging of the ureters: a systematic review"
}

\author{
T. Yeung ${ }^{1}$ (1)
}

Received: 21 February 2021 / Accepted: 8 March 2021 / Published online: 21 March 2021

(c) Springer Nature Switzerland AG 2021

\section{Dear Sir}

I read with interest the article entitled "Currently available and experimental dyes for intraoperative near-infrared fluorescence imaging of the ureters: a systematic review" by Slooter et al. [1]. In the discussion, the authors state that methylene blue detection is by near-infrared (NIR) fluorescence. However, methylene blue is excited at $660 \mathrm{~nm}$ and emits light at $700 \mathrm{~nm}$, which is not routinely captured by NIR laparoscopes. In the two studies which were quoted by the review [2, 3], we used an in-house fluorescence capable laparoscope that was tuned to the $660 \mathrm{~nm}$ wavelength to detect fluorescence from methylene blue. We were unable to detect methylene blue fluorescence using the NIR setting. Currently, commercially available fluorescence laparoscopes are tuned to the NIR range only. We look forward to the development and distribution of commercially available fluorescence laparoscopes that can detect multiple wavelengths, which will allow more widespread use of methylene blue as a fluorescence dye to identify the position of ureters intra-operatively.

\section{Declarations}

Conflict of interest Trevor Yeung has provided consultancy services to Deallus Consulting.

\section{References}

1. Slooter MD, Janssen A, Bemelman WA, Tanis PJ, Hompes R (2019) Currently available and experimental dyes for intraoperative near-infrared fluorescence imaging of the ureters: a systematic review. Tech Coloproctol 23(4):305-313

2. Yeung TM, Volpi D, Tullis ID, Nicholson GA, Buchs N, Cunningham $C$ et al (2016) Identifying ureters in situ under fluorescence during laparoscopic and open colorectal surgery. Ann Surg 263(1):e1-2

3. Barnes TG, Hompes R, Birks J, Mortensen NJ, Jones O, Lindsey I et al (2018) Methylene blue fluorescence of the ureter during colorectal surgery. SurgEndosc 32(9):4036-4043

Publisher's Note Springer Nature remains neutral with regard to jurisdictional claims in published maps and institutional affiliations.
T. Yeung

yeungtmy@gmail.com

$1 \quad$ Nuffield Department of Surgical Sciences, University of Oxford, Oxford, UK 